\title{
AN EXAMINATION OF THE RELATIONSHIP BETWEEN ACADEMIC DISHONESTY AND PROFESSIONAL BEHAVIOR
}

\author{
Trevor S. Harding ${ }^{1}$, Honor J. Passow ${ }^{2}$, Donald D. Carpenter ${ }^{3}$ and Cynthia J. Finelli ${ }^{4}$
}

\begin{abstract}
A number of recent studies have found correlations between academic dishonesty in higher education and unethical behavior in the work settings. However, these studies have not explored the causal relationship between the underlying factors that lead to this dishonesty. This realization, and apparently high levels of cheating among engineering students, has lead us to a research hypothesis that decision making patterns about academic cheating among engineering students are positively correlated with those individuals' decision making patterns about work place ethics and responsibility. To test our hypothesis, we have developed an exploratory survey that asks questions about the respondent's decisions during opportunities to "cheat" in each of two contexts: college classrooms and work-place settings (with a special focus on engineering work settings). The survey was designed to provide qualitative data that could be used to later develop a more robust quantitative survey. This paper will present only the preliminary quantitative results from this survey.
\end{abstract}

Index Terms - academic dishonesty, engineering ethics, professional behavior

\section{INTRODUCTION}

There is little doubt that academic dishonesty has been a persistent problem in higher education for quite some time. However, there have been several studies over the last four decades that indicate that rates of cheating among engineering students are higher than for students in most other disciplines. The first significant study which examined cheating as a function of academic discipline was a 1964 survey, by Bowers, that examined the attitudes and behaviors of 5,422 college students regarding academic dishonesty [1]. Bowers found that $58 \%$ of engineering students self-reported cheating in college. This was significantly higher than all other disciplines with the exception of business students. Results from this study are shown in Table I. Two years later, Harp \& Taietz found a similar result and reported that students studying in more vocationally oriented disciplines cheated at higher rates [2]. Both Bowers and Harp \& Taietz came to the conclusion that students enrolled in more "vocationally" oriented disciplines, such as engineering, were more likely to cheat than those in more "intellectually" oriented disclipines.

In a 1996 study by McCabe, that surveyed 4,279 college students from 30 different institutions, it was clear that the more professionally oriented disciplines still experienced higher levels of cheating than the intellectually oriented disciplines [3]. In addition, it appears that the level of selfreported cheating in college, for all disciplines, had increased dramatically in the past 30 years.

In an attempt to identify the underlying causes of academic dishonesty, many researchers have explored the relationship between academic dishonesty and prior behavior, particularly cheating in high school. In the only study using a large sample, Bowers reported that $64 \%$ of students who reported cheating in high school also reported cheating in college and that $67 \%$ of students who did not cheat in high school did not cheat in college [1].

TABLE I

\begin{tabular}{l|ccc}
\multicolumn{4}{l|}{ RATES OF SELF-REPORTED CHEATING BY DISCIPLINE AND THE ORIENTATION OF THAT DISCIPLINE [1],[3] } \\
\hline Discipline & Frequency of Cheating & Frequency of Cheating & Orientation of \\
& 1964 & 1996 & Discipline \\
\hline Business & $66 \%$ & $91 \%$ & Vocational \\
Engineering & $\mathbf{5 8 \%}$ & $\mathbf{8 2 \%}$ & Vocational \\
Education & $52 \%$ & - & Vocational \\
Social Sciences & $52 \%$ & $73 \%$ & Intellectual \\
Fine / Applied Arts & $50 \%$ & - & Intellectual \\
Natural Sciences & $47 \%$ & $71 \%$ & Intellectual \\
History & $43 \%$ & - & Intellectual \\
Humanities & $39 \%$ & - & Intellectual \\
Language & $37 \%$ & - & Intellectual \\
Other & - & $73 \%$ & NA \\
\hline
\end{tabular}

\footnotetext{
${ }^{1}$ Trevor S. Harding, Kettering University, Manufacturing Engineering, Flint, MI 48504, tharding@kettering.edu

${ }^{2}$ Honor J. Passow, University of Michigan, School of Education, Ann Arbor, MI 48109, hpassow@umich.edu

${ }_{3}^{3}$ Donald D. Carpenter, Lawrence Technological University, Southfield, MI 48075, carpenter@1tu.edu

${ }^{4}$ Cynthia J. Finelli, University of Michigan, Center for Research on Learning and Teaching, Ann Arbor, MI 48109
} 


\section{Session}

In a study based on their Theory of Planned Behavior, Beck and Ajzen pointed out that prior and future behavior are only correlated to the extent that the underlying determinants, such as attitudes, subjective norms, perceptions of behavioral control and intentions, have not changed over time [4]. Thus, if a correlation exists between high school cheating and college cheating, one must presume that influences other than situational factors must be at work in a student's decision to cheat. In such a case, there should be correlations between academic dishonesty and other deviant behaviors as well. Several studies have indeed found correlations between academic dishonesty in college and deviant behavior including risky driving [5], theft from employers [6], shoplifting [4], alcohol abuse [7] and cheating on income taxes [8].

These findings suggest that there are certain common factors that influence an individual's decision to participate in deviant behaviors, including academic dishonesty. It is possible that the same factors may influence decision making patterns at the professional level. Though limited data exists in regards to decision making patterns, behavioral correlations have been identified. For example, in a study of 1,051 business students, it was found that students who selfreported engagement in dishonest acts in college were more likely to report engaging in dishonest acts in the workplace $(\mathrm{R}=0.66, \rho<0.01)[9]$. Therefore, it appears that unethical behavior in college does carry over into professional settings for many individuals. If true, this finding suggests that disciplines with the highest rates of self-reported cheating, such as engineering, are likely matriculating graduates who have a higher likelihood of engaging in unethical behavior during professional practice.

Our analysis of this research leads us to a hypothesis that decision making patterns about academic cheating among engineering students are positively correlated with those individuals' decision-making patterns about workplace ethics and responsibility. To test our hypothesis, we have developed an exploratory survey which asks respondents about decisions during opportunities to "cheat" in each of two contexts: college classrooms and workplace settings. For each context, respondents were asked to consider a specific instance in which they had been tempted to cheat, what pressures they felt to cheat or not to cheat in this specific instance, and ultimately what decision they made in this specific instance. The survey also asks respondents to estimate how frequently their peers have cheated in both the classroom and the workplace. The survey was designed to provide primarily qualitative data (with some quantitative data) that could later be used to develop a more robust quantitative-only survey. The data presented in this paper represent only the quantitative aspects of this exploratory survey, and should be viewed in this light.

\section{METHODS}

\section{Sample Description}

A total of 130 students enrolled at two technically-oriented private universities responded to the survey. Altogether, 67 students responded from school A and 63 from school B. Because we wished to examine the relationship between unethical behavior in college and the workplace, first year students were not included in the sample due to their lack of experience in either setting. The sample consisted of $2^{\text {nd }}$ year $(7 \%), 3^{\text {rd }}$ year $(42 \%), 4^{\text {th }}$ year $(33 \%)$ and $5^{\text {th }}$ year $(16 \%)$ undergraduate students. Respondents from school B were on average further along in their studies $(\mathrm{t}=-4.48, \rho<0.001)$.

Self-reported grade point average (GPA) was used as a measure of academic achievement for the sample. However, the two schools in the study each use a different grading system. School A reported an average GPA of 86.6 $(\sigma=4.35)$, while school B reported an average GPA of 3.09 $(\sigma=0.44)$. An examination of school A's student handbook indicates that these two achievement levels are roughly equivalent.

Because we are interested in students' behavior in the work place, the extent to which respondents work full-time is an important variable. Participants in the study reported working full-time an average of 6.78 months $(\sigma=2.97)$ during the last academic year, and an average of 38.7 hours per week $(\sigma=10.8)$ during this time. These numbers include 2 respondents $(1.5 \%$ of sample) who indicated they had not worked at all in the past year. $70 \%$ of the sample reported working 6 months per year or less $(46 \%$ reported working exactly 6 months). $32.3 \%$ of the sample reported working 40-75 hours per week, the remainder working less than 40 hours per week. It should be noted that students at school B reported working more months during the academic year (School A: mean=6.04 months/yr, School B: mean=7.60 months/yr; $\mathrm{t}=-3.08 ; \rho=0.003$ ), but working fewer hours (School A: mean=42.6 h/wk, School B: mean $=34.3 \mathrm{~h} / \mathrm{wk}, \mathrm{t}=$ $4.75, \rho<0.001)$. Because both groups had considerable work-related experience over the past year, it was not felt that these differences would have a significant bearing on the results of this study.

\section{Survey}

Participants completed a 13-item questionnaire consisting of three sections. The first section contained questions related to the respondents' background including GPA, extent to which they worked in the past year and how frequently they cheated in high school. The second section dealt with issues relating to college cheating, and the third section of the questionnaire dealt with work place behavior.

As with any study on deviant behavior which uses a self-report questionnaire approach, underreporting due to social desirability is a concern [10]. Despite this possible 
source of error, there is evidence that in many situations selfreports of dishonest behaviors can be accurate [11]. In addition, where participants were asked to reveal sensitive information, questions were framed in such a way that the behavior was assumed, which has been shown to reduce social desirability [12]. For example, the question "How frequently did you cheat on coursework during an average term in high school?" assumes that the behavior occurred.

As a final measure to reduce the effects of social desirability, great care was taken to develop protocols that assured respondent anonymity. Participants filled out the questionnaire in their classrooms. The questionnaire was distributed by one of the authors of this paper who briefly discussed the nature of the research and the participants' rights (this information was also included in writing on the survey). The proctor left the room while participants completed the questionnaire. Respondents were asked to complete the surveys and place them in one large plain envelope when finished. The envelope was sealed and returned to a department administrative assistant who delivered it to the proctor for inclusion in the data set. These protocols, as well as the survey itself, were approved by an institutional review board for the behavioral sciences.

\section{Variables}

This paper will only describe results from the quantitative data collected from the questionnaire. In the first section of the questionnaire, a measure of student age, based on year in college, was obtained by asking participants to select from one of 5 response alternatives: $1^{\text {st }}$ year, $2^{\text {nd }}$ year, $3^{\text {rd }}$ year, $4^{\text {th }}$ year and $5^{\text {th }}$ year. Level of achievement was measured by asking respondents to indicate their grade point average using either a 100-point or 4-point scale depending on the school they attended. Respondents were also asked to indicate how many months they had worked full-time during the past year and how many hours per week they worked during this time. Finally, as a measure of past behavior, respondents were asked to indicate on average how frequently they had cheated in high school during a given term by checking one of four response options: never, once, a few times and frequently.

In the second section of the questionnaire, students were asked "How many times were you tempted to cheat (this does not mean that you necessarily cheated, only that you were tempted) on any of the following during your most recent term in college?" Students indicated the frequency they were tempted to cheat on several forms of assessment (e.g. homework, term paper, lab report, computer program, team project, test or quiz, final exam and other) by checking one of 5 different responses: never, once, 2-5 times, 5-10 times and $10+$ times. Participants were also asked to consider the list of scenarios described above, select one in which they had recently been tempted to cheat and indicate whether they had or had not cheated. The questionnaire also asked respondents to indicate what pressures they felt in this situation, how they came to their final decision and what the consequences might be for someone who cheats in this way. This free-response (or short-answer) information is not included in this paper. Finally, respondents were asked "In your opinion, what percentage of your classmates cheats?".

In the third section of the questionnaire, respondents were asked "How many times have you ever been tempted to do any of the following in a paid work situation?". Respondents were asked to indicate how frequently they had been tempted to participate in inappropriate professional behavior (e.g. falsifying records, lying about work quality, ignoring quality problems, not reporting safety problems, taking credit for someone else's work, accepting improper gifts from vendors, improperly using company supplies and other) by checking one of five response options: never, once, 2-5 times, 5-10 times and 10+ times. Participants were also asked to consider the list of scenarios described above, select one in which they had recently been tempted to participate and indicate whether they had or had not participated. The questionnaire also asks respondents to indicate what pressures they felt in this situation, how they came to their final decision and what the consequences might be for someone who behaves in this way. This information is not included in this study. Finally, respondents were asked to identify the nature of their work environment (e.g. engineering, retail, trades, etc.), and "In your estimation, what percentage of your coworkers participates in the activities listed in question \#10?".

\section{RESULTS}

\section{Academic Dishonesty}

Table II presents the self-reported frequency with which respondents cheated, on average, during a given term in high school. The majority of respondents indicated that they cheated at least a few times per term, and $79.2 \%$ of the respondents indicated that they cheated at least once.

TABLE II

SELF-REPORTED FREQUENCY OF HIGH SCHOOL CHEATING DURING AN
\begin{tabular}{l|l}
\multicolumn{2}{c}{ AVERAGE TERM } \\
\cline { 2 - 2 } Frequency & \\
\hline Never & $20.0 \%$ \\
Once & $15.4 \%$ \\
A Few Times & $53.8 \%$ \\
Frequently & $10.0 \%$ \\
\hline
\end{tabular}

Respondents were also asked to indicate what percentage of their peers cheats in college. The response from the sample as a whole was that $49.3 \%$ of their peers cheat. However, the spread in this data was considerable $(\max .=100 \%, \min .=1 \%, \sigma=26.7 \%)$ indicating that there are distinct differences in how students perceive the behaviors of others. This may be caused by differences in peer groups, or students may be reflecting their own behavior onto their 
peers. There is evidence from other studies that points to a strong correlation between perception of peer behavior and an individual's own frequency of cheating [13],[14],[15].

Because we were specifically interested in decisions during opportunities to cheat, respondents were asked to indicate how frequently they were tempted to cheat on various forms of assessment during their most recent term in college. Frequency data is presented in Table III. Average scores for these assessments, based on a 5-point Likert scale, are shown in the far right column. Respondents indicated that they were most frequently tempted to cheat on homework, followed by lab reports, and then tests or quizzes. Participants reported that they were least likely to be tempted to cheat on team projects, term papers and final exams. Average scores were significantly different as determined by a Friedman non-parametric test $\left(\chi^{2}=171.3\right.$, $\mathrm{df}=6, \mathrm{p}<0.001)$. These results are not surprising as our previous data has shown that respondents' perceptions of cheating are significantly different by context [16]. These results appear to counter the argument by McCabe [3] that increased levels of cheating in engineering students is a result of greater use of team-based assignments in engineering courses.

Participants were asked to consider a situation in which they were recently tempted to cheat and to report what considerations they made during their decision of whether or not to cheat in this instance. This information is not included in this paper; however, we can report that $36.2 \%$ of respondents indicated that they decided to go through with their plan to cheat, while $50.0 \%$ chose not to $(13.8 \%$ provided no response). From Table III it is apparent that in certain contexts (homework, lab reports, tests/quizzes and computer programs) more respondents indicate being tempted to cheat than indicated actually cheating in the specific situation they were considering, suggesting many more students are tempted to cheat than actually do. While these data are certainly not conclusive, they suggest that more research on the decision process is needed to further clarify how some students, under certain conditions, are able to avoid temptations to cheat, while others are not.

\section{Unethical Professional Behavior}

Given that we are interested in the behavior of the respondents in engineering work settings, it was necessary to have respondents identify the work situation they participated in during the past year. For the sample under investigation, $40 \%$ of respondents indicated that they had most recently been employed in an engineering occupation. A further $10 \%$ indicated retail/restaurant/service and $10 \%$ indicated trades/construction. Respondents who did not work for pay during the last year were asked to skip over this section of the survey, which accounted for $30 \%$ of participants. This does not mean that $30 \%$ of students did not work during the last year. If this were true, the average reported number of hours worked per week should have been considerably lower than 40 hours. Since this was not the case, we suspect that most respondents had worked during the past year, but a substantial number chose not to complete this portion of the survey for other reasons.

Similar to the question regarding peers' behavior in college, respondents were asked to estimate how frequently their peers' participated in activities which violated their companies' policies. According to the data, respondents believe that an average of $33.6 \%$ of their peers' violate company policies. The scatter in this data is considerable (max. $=100 \%$, $\min .=0 \%, \sigma=29.5 \%$ ).

Again, we asked respondents to indicate under which work-related scenarios they had been tempted to violate company policies in the past year. This data is presented in Table IV. From this table it is apparent that participants were most frequently tempted to use company supplies or equipment improperly. This is in line with research indicating that employee theft is the primary source of crime-related losses in business [9]. As many as $48.8 \%$ of respondents indicated that they were tempted to use company supplies or equipment improperly at least once during the last year.

The second most frequent scenario respondents reported was that of being tempted to falsify records $(31.5 \%)$ such as time sheets, expense reports and quality assurance documents, at least once during the past year. This was followed by ignoring quality problems $(22.4 \%)$, lying about the quality of one's work $(16.9 \%)$, ignoring safety problems $(15.2 \%)$, accepting improper gifts $(11.2 \%)$ and finally taking credit for someone else's work (9.6\%). Average scores were significantly different as determined by a Friedman non-parametric test $\left(\chi^{2}=111.0, \mathrm{df}=6, \mathrm{p}<0.001\right)$.

TABLE III

FREQUENCY RESPONDENTS WERE TEMPTED TO CHEAT ON VARIOUS ASSESSMENTS DURING THEIR LAST COLLEGE TERM

\begin{tabular}{l|cccccc}
\hline Assessment & Never & Once & $\begin{array}{c}2-5 \\
\text { Times }\end{array}$ & $\begin{array}{c}5-10 \\
\text { Times }\end{array}$ & $\begin{array}{c}10+ \\
\text { Times }\end{array}$ & $\begin{array}{c}\text { Average } \\
\text { Score }^{*}\end{array}$ \\
\hline Homework & 23.1 & 17.7 & 33.8 & 15.4 & 7.7 & $\mathbf{2 . 6 6}$ \\
Lab Report & 50.8 & 12.3 & 24.6 & 6.2 & 4.6 & $\mathbf{2 . 0 0}$ \\
Test/Quiz & 42.3 & 20.8 & 29.2 & 3.8 & 1.5 & $\mathbf{1 . 9 9}$ \\
Computer Program & 60.0 & 11.5 & 16.9 & 4.6 & 3.8 & $\mathbf{1 . 7 7}$ \\
Final Exam & 63.8 & 20.0 & 10.0 & 2.3 & 1.5 & $\mathbf{1 . 5 4}$ \\
Term Paper & 71.5 & 13.8 & 10.0 & 1.5 & 1.5 & $\mathbf{1 . 4 5}$ \\
Team Project & 79.2 & 5.4 & 9.2 & 2.3 & 1.5 & $\mathbf{1 . 3 8}$ \\
\hline * - Average scoring based on: $1=$ Never, $2=$ Once, $3=2-5$ Times, $4=5-10$ Times, 5 = 10+ Times
\end{tabular}


Session

TABLE IV

FREQUENCY RESPONDENTS WERE TEMPTED TO VIOLATE WORK PLACE POLICIES DURING A GIVEN TERM IN COLLEGE

\begin{tabular}{|c|c|c|c|c|c|c|}
\hline Scenario & Never & Once & 2-5 Times & $\begin{array}{c}5-10 \\
\text { Times }\end{array}$ & $\begin{array}{c}10+ \\
\text { Times }\end{array}$ & $\begin{array}{c}\text { Average } \\
\text { Score }\end{array}$ \\
\hline Improper Use of Company Supplies & 51.2 & 14.4 & 25.6 & 3.2 & 5.6 & 1.98 \\
\hline Falsify Records & 64.6 & 6.9 & 17.7 & 2.3 & 4.6 & 1.70 \\
\hline Lie About Work Quality & 79.2 & 5.4 & 6.2 & 3.8 & 1.5 & 1.37 \\
\hline Ignore Safety Problems & 84.8 & 8.0 & 5.6 & 1.6 & 0.0 & 1.24 \\
\hline
\end{tabular}

Finally, respondents were asked to consider a specific situation at work in which they had been tempted to violate company policy and to report what considerations they made during their decision of whether or not follow through on this temptation. As before, this qualitative data is not reported here. However, we can report that of the participants who indicated they had been tempted to violate company policy in the past year, 30\% went through with their plans. $15.4 \%$ opted not to go through with their plans, and the remaining $10.8 \%$ followed some other course of action (from the open responses, some participants indicated that they had been tempted by other individuals, suggesting that an alternative course of action could be to report these accomplices). Altogether, $43.8 \%$ provided no response to this question.

\section{Comparative Analysis}

From the data presented above it is apparent that the undergraduate students in our sample are less frequently tempted to violate work place policies than is the case with academic policies. Using a Friedman test, we can compare differences in frequencies of non-parametric data such as this. Table V presents mean ranks, as determined in the Friedman test. All differences were significant $\left(\chi^{2}=325.8\right.$, $\mathrm{p}<0.001)$. This data shows that respondents were more frequently tempted to cheat in school than to be tempted to violate a work place policy. This may be a consequence of students having more opportunities to cheat in school than they have at work. However, based on a cursory examination of the free-response questions in the survey, it is apparent that a number of factors mediate the likelihood that they would consider an unethical action. For many students there is an increased perception of punishment in the work place, including loss of employment. For others there is an affective response to the idea of "cheating" at work to get ahead. They believe this violates their own work ethic and would not consider it. And for others, their appears to be greater internality of Locus of Control, the extent to which an individual believes that he or she has personal control over the reinforcements of their positive behaviors. In other words, individuals with a highly internal locus of control strongly believe that they have direct influence on the benefits of their positive behavior at work. While these factors should not necessarily affect the temptation to violate work place policies, but rather the decision to succumb to this temptation, it is possible that respondents were unable to separate whether they were tempted from their own reaction to the temptation while completing the survey.

TABLE V

FRIEDMAN'S TEST OF FREQUENCY RESPONDENTS WERE TEMPTED TO Violate ACAdEMiC AND Work Place Policies (WORK PlaCE SCENARIOS IN BOLD)

\begin{tabular}{lc}
\hline Scenario & Mean \\
& Rank $^{*}$ \\
\hline Homework & 11.08 \\
Test or Quiz & 9.17 \\
Improper Use of Company Supplies & $\mathbf{8 . 7 2}$ \\
Lab Reports & 8.67 \\
Computer Program & 7.99 \\
Falsify Work Records & $\mathbf{7 . 5 4}$ \\
Final Exam & 7.45 \\
Term Paper & 7.01 \\
Ignore Quality Problems & $\mathbf{6 . 5 9}$ \\
Lie About Work Quality & $\mathbf{6 . 4 6}$ \\
Team Projects & 6.45 \\
Not Report Safety Problems & $\mathbf{6 . 1 4}$ \\
Accept Improper Gifts & $\mathbf{5 . 9 3}$ \\
Take Credit for Other's Work & $\mathbf{5 . 8 0}$ \\
\hline$\left.{ }^{*} \chi^{2}=325.8, p<0.001\right)$ &
\end{tabular}

We might also consider a comparison of the frequencies with which participants recalled a tempting situation and either went through with their plans or did not. Table VI shows that despite differences in frequency of temptation, nearly the same number of respondents indicated that they had cheated/violated work place policies. It should be noted that a large number of respondents opted not to respond to this question as it pertains to work place behavior.

TABLE VI

Percentage of Respondents that Did OR Did Not Go Through With Plans To Cheat or Violate Work Place Policies

\begin{tabular}{lcccc}
\hline Setting & $\begin{array}{c}\text { Went } \\
\text { Through } \\
\text { with Plan }\end{array}$ & $\begin{array}{c}\text { Did Not Go } \\
\text { Through } \\
\text { With Plan }\end{array}$ & Other & $\begin{array}{c}\text { No } \\
\text { Reponse }\end{array}$ \\
\hline Academic & 36.2 & 50.0 & 0.0 & 13.8 \\
Work Place & 30.0 & 15.4 & 10.8 & 43.8 \\
\hline
\end{tabular}

This data also indicates that in the tempting situations that the respondents were considering many chose not to cheat, and a smaller percentage chose not to violate their 


\section{Session}

company's policies. While the limited literature on the subject has quantified a relationship between academic and work place dishonesty, it has not substantially identified the underlying factors that allow some individuals to avoid these temptations.

In examining the relationship between past and future behavior, no correlation was found between cheating in high school and a decision to cheat in a particular situation in college $(\mathrm{R}=-0.117, \mathrm{p}=0.22)$ or between cheating in high school and a decision to violate company policies $(\mathrm{R}=$ 0.045, $\mathrm{p}=0.71$ ). It should be kept in mind that these correlations are based on aggregated recollections of the frequency of cheating in high school and whether or not an individual decides to cheat/violate workplace policy in one specific situation.

Further, no correlation was found between students choosing to cheat in a specific situation in college and those deciding to follow through on a plan to violate company policies at work $(\mathrm{R}=0.059, \mathrm{p}=0.63)$. Despite this result, we may yet find relationships among the factors that influence the decisions made by the respondents when we more completely analyze the qualitative data not presented here.

We did observe a strong correlation between the reported percentage of respondents' peers that cheated in college and the percentage of peers that violated policies at work ( $\mathrm{R}=0.317, \mathrm{p}=0.001)$. In addition, there is a strong correlation between the perception that one's peers cheat in college and whether or not the individual decided to cheat in the situation they were considering $(\mathrm{R}=0.288, \mathrm{p}=0.002)$. No such correlation was found between perceptions of peers' behavior and the decision to violate policies in the work place $(\mathrm{R}=-0.015, \mathrm{p}==0.90)$. Whether there is a causal relationship between the decision to cheat and peer behavior is unclear, however, research suggests that the level of peer cheating and peer disapproval of cheating are among the strongest influences on students' decisions to cheat [15]. Moreover, it is possible that students perceive their work position as more tenuous than that at school, and therefore, are more reluctant to violate work place policy, even if they perceive that others at work do so. This may be a further argument for why our quantitative data did not show a relationship between decisions to cheat in college and decisions to violate work place policies.

\section{CONCLusions}

The primary finding in this work is that there does not appear to be a quantitative correlation between the decision to cheat in a specific situation in college and decisions to violate work place policies in a specific situation. This suggests that the relationship between cheating in college and unethical behavior in professional practice may not be straightforward or simple. However, we also believe that the validity of the instrument used in this preliminary study could be considerably improved. One potential weakness with the survey is that we are attempting to make correlations among data based on students' behavior in a variety of scenarios. It may be preferrable to collect data from students who have only been involved in one specific set of scenarios (one for academic dishonesty and one for work-place behavior) to eliminate any variability caused by differences in scenario. An alternative would be to provide respondents with a set of hypothetical scenarios, regardless of whether they have or have not been involved. This would result in more data, but would necessitate making conclusions based on perceived, rather than actual, behavior. Furthermore, as we continue to explore the qualitative data not reported here relationships between the underlying factors that influence ethical decision making in both academic and work place settings will be uncovered.

\section{REFERENCES}

[1] Bowers, W. J., Student Dishonesty and its Control in College, Bureau of Applied Social Research, Columbia University, 1964.

[2] Harp, J. and Taietz, P., "Academic Integrity and Social Structure: A study of cheating among college students", Social Problems, 13, 1966, 365-373.

[3] McCabe, D. L., "Classroom Cheating Among Natural Science and Engineering Majors", Science and Engineering Ethics 3, 433-445, 1997.

[4] Beck, L. and Ajzen, I., "Predicting Dishonest Actions Using the Theory of Planned Behavior", Journal of Research in Personality, 25, 285-301, 1991

[5] Blankenship, K. L. and Whitley, B.E., "Relation of General Deviance to Academic Dishonesty", Ethics and Behavior, 10, 1, 1-12, 2000.

[6] Hilbert, G. A., "Involvement of Nursing Students in Unethical Classroom and Clinical Behaviors", Journal of Professional Nursing, 1, 230-234, 1985.

[7] Kerkvliet, J., "Cheating by Economics Students: A comparison of survey results", Journal of Economic Education, 25, 121-133, 1994.

[8] Fass, R. A., "Cheating and Plagiarism", Ethics and Higher Education, W. W. May, ed., New York: Macmillan, 170-184, 1989.

[9] Nonis, S. and Swift, C.O., "An Examination of the Relationship Between Academic Dishonesty and Workplace Dishonesty: A Multicampus Investigation", Journal of Education for Business, 6977, 2001.

[10] Edwards, A. L., Techniques of Attitude Scale Construction, New York: Appleton-Century-Crofts, 1957.

[11] Himmelfarb, S. and Lickteig, C., "Social Desirability and the Randomized Response Technique", Journal of Personality and Social Psychology, 43, 4, 710-717, 1982.

[12] Sudman, S. and Bradburn, N.M., Asking Questions, San Francisco: Josey-Bass Publishers, 1983.

[13] McCabe, D.L. and Trevino, K.L., "Academic Dishonesty: Honor Codes and other contextual influences", Journal of Higher Education, 64, 5, 522-538, 1993.

[14] McCabe, D.L. and Bowers, W.J., "The Relationship between Student Cheating and College Fraternity or Sorority Membership", NASPA Journal, 33, 4, 280-291, 1996.

[15] McCabe, D.L. and Trevino, L.K., "Individual and Contextual Influences on Academic Dishonesty: A multicampus investigation", Research in Higher Education, 38, 3, 379-396, 1997.

[16] Finelli, C.J., Harding, T.S., Carpenter, D.D. and Passow, H.J., "Students Perceptions of the Certainty and Deterrent Effect of Potential Consequences to Cheating on their Own Decision to Cheat", Proc. American Society for Engineering Education Annual Conference, Nashville, June 2003. 